\title{
Macroaggregates in the packed red blood cell unit during transfusion
}

\author{
Seung Uk Bang, Sang Mook Lee, Sae-Cheol Oh, Kyudon Chung, and Dong Joo Lee \\ Department of Anesthesiology and Pain Medicine, College of Medicine, The Catholic University of Korea, Daejeon St. Mary's \\ Hospital, Daejeon, Korea
}

Blood has to pass through the following series of stages before it can be used for a transfusion: donor screening, blood collection, component preparation, preservation, storage and release. Additionally, packed red blood cells (PRBCs) during the release stage have to pass through the following multiple stages: blood transfusion service form, inspection, issuing, and reissuing. The inspection stage is done before the transfusion is issued and shipped to other facilities. At this stage, the date, donor, color, appearance, and expiration date of the blood are certified and recorded. Each stage has standards and only blood that passes each of them can be used for transfusions to patients [1,2].

In these stages, most incompatible blood products are excluded; thus, it is rare to transfuse these incompatible blood products to patients. Because of the low incidence of complications related to blood transfusions, blood products for transfusions are often given to patients using only blood matching and minimal incompatibility tests based on information from the patient. However, we found a quantity of macroaggregates in blood bags during transfusions despite passing the pretransfusion test.

A 75-year-old male was scheduled for common femoral artery bypass operation under general anesthesia to treat arteriosclerosis of obliterans of the left external iliac artery. Preanesthetic checkup showed no significant abnormalities. About an hour after the operation, it was decided that a PRBC transfusion was needed due to continuous bleeding. Twenty minutes later, the blood arrived and the overall conformity between the donor and the patient-name, sex, age, and blood type- was checked. A mixture of $0.9 \%$ normal saline $200 \mathrm{ml}$ and PRBC was transfused to the patient using a standard blood transfusion set (transfusion set-s; Doowon Medical, Korea). However, this did not work and another attempt with a different transfusion set also failed. Upon closer inspection, more than 20 dark-red mucus clots were found inside the PRBC bag (Fig. 1). The color of the clots was dark red and the size was variable around $1.5 \mathrm{~cm}^{2}$. After an immediate inquiry to the blood bank, we were advised to replace the PRBC because the dark-red mucus clots turned out to be macroaggregates which are not normal for a blood transfusion. The operation was completed safely with a new PRBC bag, injecting 7 units of PRBC and 3 units of fresh frozen plasma. The patient left the hospital 3 weeks later without any complications.

Although it is common that macroaggregates might exist in whole blood with profuse plasma and platelets, those inside PRBC bags are quite rare and thus, scarcely reported and studied. Moreover, most of them in PRBC bags are discovered before the release stage consisting of platelets, leucocytes, and some fibrins without toxins, and infectious agents [2-4].

From the microscopic observation in our case in which red blood cells (RBCs), neutrophils, macrophages, fibrins, and cell debris aggregated and clotted with each other, the macroaggregates might have been formed by a process in which the leucocytes and cell debris fused to fibrins in small amounts of aggregated platelets. We assume there are three risk factors for this phenomenon. First, macroaggregates might have already been developed by unknown causes, and the inspector could have missed them until the release stage. Inspection failure by the blood bank can never be completely excluded. Second, as citrate phosphate dextrose adenine (CPDA-1) is broadly used,

Corresponding author: Sang Mook Lee, M.D., Department of Anesthesiology and Pain Medicine, College of Medicine, The Catholic University of Korea, Daejeon St. Mary's Hospital. 520-2, Daeheung-dong, Jung-gu, Daejeon 301-723, Korea. Tel: 82-42-220-9046, Fax: 82-42-242-3500, E-mail: ismoogi@catholic.ac.kr

(c) This is an open-access article distributed under the terms of the Creative Commons Attribution Non-Commercial License (http:// creativecommons.org/licenses/by-nc/3.0/), which permits unrestricted non-commercial use, distribution, and reproduction in any medium, provided the original work is properly cited. 

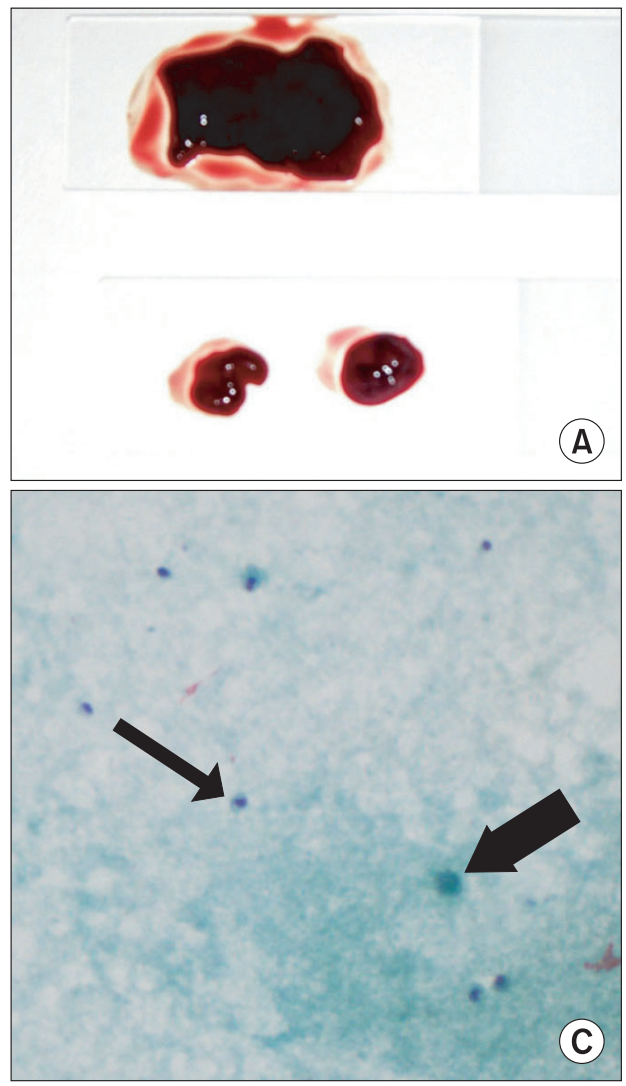

(C)
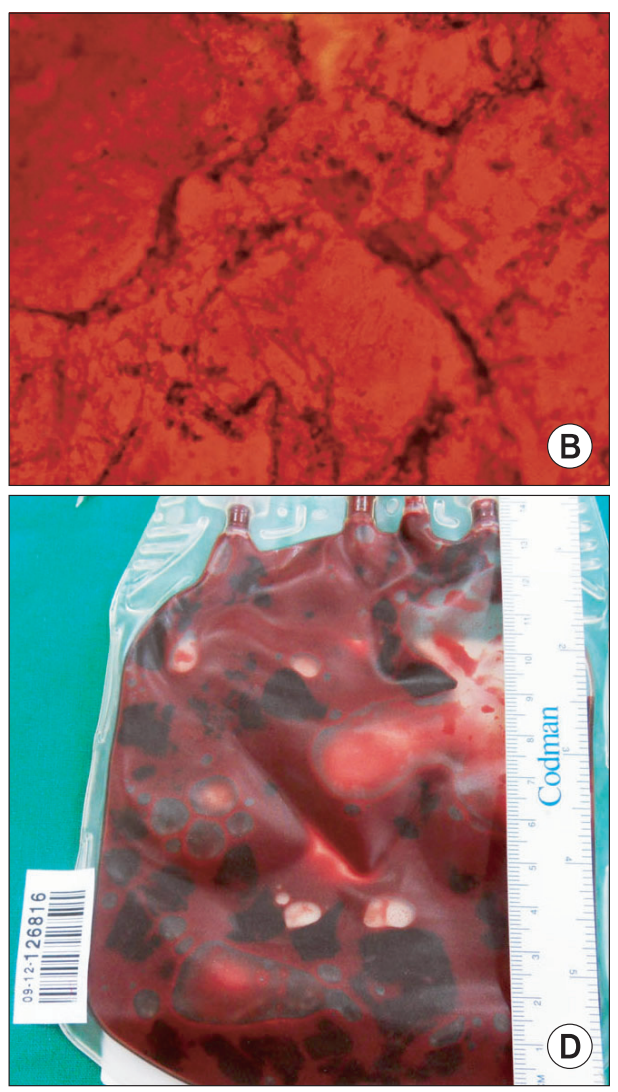

Fig. 1. Gross and microscopic findings of the macroaggregates. (A) Gross appearance. (B) Fibrin strands with RBCs and cellular debris (Pap stain, $\times 200$ ). (C) Neutrophils and macrophages. Thin arrow: neutrophil, Thick arrow: macrophage (H\&E stain, $\times 400)$. (D) Macroaggregates in PRBC bag. an imperfect mixture of CPDA-1 could be another factor. Although the proportion of anticoagulant is comparatively low, the risk of creating macro \& microaggregates is high when we using CPDA-1(using $14 \mathrm{ml}$ per $100 \mathrm{ml}$ of blood). That is, CPDA-1 must be mixed thoroughly because the quantitative mixing proportion of CPDA-1 is quite low. Third, the storage period could be another factor. The longer the blood is kept, the thicker the concentration of the acid phosphate in the blood, which accelerates the formation of macroaggregates from severe cellular damage and breakdown [5]. The problematic blood in our case was taken on May 15, 2012 and the expiration date was June 18. The blood transfusion was on May 26. As mentioned above, thirteen days might have been enough time to form macroaggregates.

Most blood transfusions are routinely done in the operating room at a hospital but the risk of complications is considerably high. Thus, examination of all the stages related to blood transfusions is indispensable for preventing those complications. Additionally, macroscopic inspection before the transfusion is important no matter what the results of the compatible pretransfusion test are. In addition, to prevent the complication of macro \& microaggregates, standard filters should be used based on proper instructions, and it is advisable to use micro filters for high-risk cases.

\section{References}

1. Brecher ME. Collection, preparation, storage and distribution of components from whole blood donations, in Technical Manual. 15th ed. Bethesda, American Association of Blood Banking. 2005, pp 175-202.

2. Robertson M, Boulton FE, Doughty R, MacLennan JR, Collins A, McClelland DB, et al. Macroaggregate formation in optimal additive red cells. Vox Sang 1985; 49: 259-66.

3. Rentas FJ, Macdonald VW, Rothwell SW, McFaul SJ, Asher LV, Kennedy AM, et al. White particulate matter found in blood collection bags consist of platelets and leukocytes. Transfusion 2004; 44: 959-66.

4. Hillyer CD, Roback JD, Hillyer KL, Josephson CD, Page PL. Description and investigation of white particulate matter in additive solution-1 red blood cell units. Transfusion 2004; 44: 977-83.

5. Truter EJ, Rossouw JJ, Böhm L. Studies on the ultrastructure of blood cells and the microaggregate fraction in stored human blood. Intensive Care Med 1981; 7: 115-9. 